\title{
Precipitation kinetics in a severely plastically deformed 7075 Aluminium alloy
}

\author{
A. Deschamps ${ }^{1}$, F. De Geuser ${ }^{1}$, Z. Horita ${ }^{2,3}$, S. Lee ${ }^{2,3}$, G. Renou ${ }^{1}$ \\ ${ }^{1}$ SIMAP, Grenoble INP- CNRS - UJF, BP 75, 38402 St Martin d’Hères Cedex, France \\ ${ }^{2}$ Department of Materials Science and Engineering, Faculty of Engineering, Kyushu University, \\ Fukuoka 819-0395, Japan \\ ${ }^{3}$ WPI, International Institute for Carbon-Neutral Energy Research (WPI-I2CNER), Kyushu \\ University, Fukuoka 819-0395, Japan
}

\begin{abstract}
In this paper we report a quantitative study, using small-angle X-ray scattering, of the precipitation kinetics during ramp heating and isothermal ageing in an AA7075 Aluminium alloy processed by high-pressure torsion. The precipitation behaviour has been compared with that of the same material processed in a conventional manner and observations are supplemented by transmission electron microscopy for precipitate and grain size characterization using automated crystal orientation mapping. After severe plastic deformation and natural ageing the material is shown to contain a high density of GP zones. During ageing, the precipitate size distribution becomes bimodal, with small precipitates behaving similarly to that of the conventionally processed material and large ones associated to the crystalline defects and reaching large sizes at considerably lower temperatures and shorter times as compared to the conventionally processed material.
\end{abstract}

Keywords: Aluminium alloys; severe plastic deformation; high pressure torsion; precipitation; small-angle X-ray scattering

\section{Introduction}

Severe plastic deformation (SPD) is now a well established way to make materials with extremely small grain sizes and resulting high strength [1]. Using a great variety of processes (the most studied being Equal-Channel Angular Pressing (ECAP) [2] and High-Pressure Torsion (HPT) [3], alongside many others (such as accumulative roll bonding, cryorolling, multiaxial channel compression, ...), grain size is reduced to a range between 100 and $500 \mathrm{~nm}$ and brings the materials to very high strength.

In Aluminium alloys, the conventional way of achieving high strength is through fine scale precipitation. Therefore it is not surprising that studying severe plastic deformation in precipitationstrengthening Aluminium alloys has attracted a large amount of interest in the last 10 years [4-31], hoping for combined strengthening between small grain sizes and precipitates (yield strength of 1 GPa has been achieved in an Al-Zn-Mg-Cu alloy processed by HPT [32]) and of increased stability of the submicron grain size by precipitate pinning [27].

Studying the combination of precipitation and SPD is a complex topic given the number of parameters that can be changed. Notwithstanding the variety of existing SPD processes, SPD can be carried out on a random solid solution (right after quenching from a solution treatment) or on a microstructure already containing precipitates. It can be carried out at cryogenic temperatures (note that only a limited number of processes allow for this), at room temperature or at temperatures where classical precipitation treatments are carried out (typically 100 to $200^{\circ} \mathrm{C}$ ). Note that the low temperature processes can usually only be carried out on solution treated materials or specimen 
fracture during SPD is difficult to avoid. SPD can be followed by a subsequent ageing treatment, with or without intermediate solution treatment. And of course the results are alloy dependent, with studies carried out on five alloy families: 7000 (Al-Zn-Mg-Cu)[4-9,15,24,27,29,31,32], 6000 (AlMg-Si)[10,14,17,23,25], Al-Cu based 2000 [12,18,20,22,26], Al-Cu-Mg based 2000 [28], Al-Cu-Li based 2000 [13,19,21].

Despite this complexity, some general rules can be summarized from the now relatively abundant literature:

- If precipitates are present before SPD, several phenomena can take place $[13,14,16,18,20,22]$ : they can be progressively fragmented and even dissolve during the deformation process, resulting in a state close to a solid solution, or continue to precipitate while being deformed together with the matrix. These processes and the competition between them are highly temperature and strain dependent.

- The microstructure resulting from room temperature SPD carried out on solution treated materials has not been fully characterised yet since the very fine grain structure prevents from observing extremely small objects with conventional tools such as electron microscopy. Some papers invoke the absence of GP zones following room temperature SPD [6] while others evidence the presence of clusters or GP zones [28,29].

- If precipitates are not present initially and SPD is carried out at elevated temperature, accelerated dynamic precipitation occurs during SPD with a rate one or two orders of magnitude faster than corresponding precipitation in the absence of SPD $[8,13,15,23-$ 25,29].

- Precipitation following SPD occurs much faster than precipitation in the coarse grained (CG) counterparts $[7,10,19]$, and in many cases the intermediate metastable phases are skipped so that the equilibrium phase is formed at much lower temperatures than in conventional ageing treatments $[12,18,22,24,26]$. Among the reported cases, the extensive formation of $\theta$ in SPD Al-Cu during a few months at room temperature is particularly remarkable [12]. Many other reports exist on the formation of $\theta$ at the grain boundaries instead of the metastable $\theta$ ' phase during medium temperature ageing $[18,22,26]$. Other systems may however behave differently. No extensive $\eta$ phase formation has been reported yet at room temperature following SPD on Al-Zn-Mg-Cu alloys, even though it is observed to form extensively at structural defects during elevated temperature ageing [29,31]. In AlCuLi alloys reports of $\theta^{\prime}$ and $\mathrm{T}_{1}$ formation exist, similarly to what is found in coarse grained materials [19,21].

- In parallel to all these phenomena, the mechanical behaviour is usually followed by hardness measurements. After moderately large deformation processes (e.g. cryorolling) materials present a strengthening behaviour similar to that of conventional ageing, however accelerated to shorter times [7]. After SPD however the hardness is already very high (about $200 \mathrm{HV}$ for most precipitation strengthening Al alloys) so that no strong further increase can be obtained. Depending on the post-SPD ageing temperature (from room temperature upwards) and the alloy family, in some cases an additional strengthening of about $50 \mathrm{HV}$ is found (Al-Zn-Mg-Cu [4,5] and Al-Cu-Li [19]), in other cases the hardness remains stable and at higher temperatures hardness decreases continuously, because strengthening is reduced by precipitate coarsening, a concurrent reduction in defect density (dislocations, microstrains) and by grain growth [7,9,17,19,26,29,33]. Several authors have proposed strategies to optimise the combination of strength and ductility by acting on the SPD parameters and subsequent ageing treatment [11,21].

Several critical parameters are invoked when discussing the effect of SPD on precipitation, even though there is a lack of quantitative understanding until now. Diffusion rates many orders of magnitude above the equilibrium ones need to be invoked to account for the rate of formation of the precipitates. This has been attributed to extremely high vacancy concentrations due to the SPD process [34,35], and concentrations of $10^{-5}$ to $10^{-4}$ have been postulated [34]. However such 
numbers are difficult to verify, since the positron annihilation technique, for instance, is sensitive in such materials to all present structural defects and proves to be difficult to interpret based on vacancy solute interactions alone [36]. Additionally, since in many cases precipitation occurs together with some grain growth, it has been postulated that grain boundary motion, sweeping solute from the matrix, may play a strong role in accelerating precipitation [12].

Until now, the study of precipitation phenomena in SPD materials has been almost exclusively carried out using transmission electron microscopy (TEM), with associated indirect techniques such as differential scanning calorimetry (DSC) and X-ray diffraction (DRX), and occasionally Atom Probe Tomography (APT) observations. However, given the very small size of the crystallites present (about $100 \mathrm{~nm}$ ), the presence of high levels of microstrains and high density of dislocations, characterising in detail microstructural states including very small precipitates proves to be extremely difficult [10], and the interpretation on the evolution of such precipitates with time or temperature remains necessarily qualitative, except for later stages of ageing where the objects become sufficiently large to be easily observed.

Small-Angle X-ray Scattering (SAXS) has been extensively used in precipitation hardening Al alloys (particularly in 7000 and 2000 series) to obtain a quantitative measurement of precipitation microstructures, both in terms of size and volume fraction, and allowing for in-situ measurements along isothermal or non-isothermal heat treatments $[37,38]$. Since this technique is sensitive to spatial variations of electron density (therefore of chemistry) within the sample, the signal is dominated by the precipitate microstructure, and the contribution of structural defects is usually negligible (except in low-contrast, low volume fraction situations, see e.g. [39]). This technique is particularly suited to observing nanometre-scale precipitation, from clusters containing a few atoms to precipitates of $10-50 \mathrm{~nm}$.

The aim of the present paper is to clarify the precipitation process in SPD materials by a quantitative evaluation of the decomposition kinetics following the SPD process. For this purpose we have chosen to restrict ourselves to what seems to be the simplest situation, namely:

- An alloy with precipitates of low aspect ratio with high contrast in atomic number with respect to the matrix, so that they are easily measured by SAXS and dominate the signal as compared to other sources of small angle scattering in the SPD material. Al-Zn-Mg-Cu alloys are best suited for this purpose as they have been extensively studied by SAXS before [40-44]. Among this alloy family AA7075 has been the subject of extensive studies by SPD $[29,31]$ and thus was our choice.

- A SPD process carried out on the material being in solid solution so that as little precipitation as possible is present prior to further heat treatments.

- A SPD process that enables deformation at strictly room temperature to limit as much as possible the evolution of the precipitation microstructure during deformation. Among the different choices HPT is known to respect best this criterion.

- Precipitation is followed during isothermal and non-isothermal ageing after extensive natural ageing of several months to minimise scatter between samples.

Measurement of precipitates by SAXS is carried out in-situ during different ageing sequences. Hardness measurements are carried out during the same heat treatments. These measurements are supplemented on selected microstructures by TEM observations. The evolution of grain microstructure during the ageing treatments was qualitatively followed by Automated Crystal Orientation Maps (ACOM) obtained from nanobeam STEM images using the ASTAR software developed at Grenoble Institute of Technology, France.

\section{Materials and experimental methods}

The 7075 alloy used in this study is the same as the one examined in an earlier investigation [45]. The alloy contains major alloying elements of $5.63 \% \mathrm{Zn}, 2.56 \% \mathrm{Mg}$ and $1.68 \% \mathrm{Cu}$ with minor 
impurity elements as $0.21 \% \mathrm{Fe}, 0.19 \% \mathrm{Cr}, 0.14 \% \mathrm{Si}, 0.05 \% \mathrm{Mn}$ and $0.02 \% \mathrm{Ti}$ (all in mass $\%$ ). The alloy was received in the form of a plate with $10 \mathrm{~mm}$ thickness after T6 treatment. Cylinders with $10 \mathrm{~mm}$ diameter and $10 \mathrm{~mm}$ height were extracted from the plate by an electrical spark discharge machine and sliced to disks with $1 \mathrm{~mm}$ thickness. The disks were then solution-treated at $490^{\circ} \mathrm{C}$ in air for 5 hours followed by quenching in water. Some of these disks were kept at room temperature for several months, resulting in a state that will be subsequently called solution treated and naturally aged (or ST+NA) and were then subjected to ageing treatments. After the disks were lightly polished on the surfaces, the other disks were processed, right after solution treatment, by HPT at room temperature under a pressure of $6 \mathrm{GPa}$ for 3 revolutions with a rotation speed of 1 r.p.m.. The HPT-processed disks were kept at room temperature (i.e., natural aging) for several months, resulting in a state that will be subsequently called HPT processed and naturally aged (or HPT+NA) and were then also subjected to ageing treatments.

SAXS experiments were carried out on a laboratory rotating anode working with a $\mathrm{Cu}_{\alpha}$ source. CCD camera data were corrected for read-out noise, distortion, flat-field, background noise. It was normalised using a reference glassy carbon sample as a secondary standard for absolute calibration [46]. In-situ experiments were carried out using a dedicated furnace in which the samples, thinned to 70-100 $\mu \mathrm{m}$, were placed. The diameter of the X-ray beam was $1 \mathrm{~mm}$, and the signal was recorded from a location placed at mid-distance between the centre and the edge of the HPT-processed disk in order to probe a reproducible microstructure from one sample to the other.

Samples for transmission electron microscopy were prepared at the same location as for the SAXS measurements (namely at mid-distance between the centre and the edge of the HPT-processed disks) by conventional mechanical polishing down to $90 \mu \mathrm{m}$ thickness, followed by double-jet electropolishing in a methanol + nitric acid solution working at $-30^{\circ} \mathrm{C}, 20 \mathrm{~V}$. Observations were carried out on a $300 \mathrm{kV}$ Jeol 3010 microscope. Orientation maps were acquired using Automated Crystal Orientation Mapping in the TEM [47]. The TEM sample was scanned with a beam size of approximately $10 \mathrm{~nm}$ without precession, at a scan rate of $35 \mathrm{fps}$ and a step size of $10 \mathrm{~nm}$. The resulting maps have a total size of $3 \mu \mathrm{m} \times 3 \mu \mathrm{m}$.

\section{Precipitation kinetics in the alloy with conventional grain size}

Before studying the precipitation kinetics in the severely deformed material, it is useful, as a reference, to evaluate that of the material processed in a conventional manner. For this purpose, the ST+NA material was subjected to three ageing treatments while recording in-situ the small-angle $\mathrm{X}$-ray scattering signal to monitor the state of precipitation. In the initial state, the precipitates have a characteristic radius of about $0.8 \mathrm{~nm}$ as determined by the SAXS signal using the methodology detailed in [48]. Following the detailed work on a coarse-grained similar alloy by Sha and Cerezo [49], and the observations on severely plastically deformed similar alloy [50], these small precipitates formed during room-temperature ageing will be subsequently assumed to be GP zones. Their volume fraction is such that a pronounced interference maximum is observed in the smallangle scattering spectrum (figure 1(a)). This feature is characteristic of a volume fraction sufficient so that the distance between precipitates is of the same magnitude as their size, so that the smallangle scattering signal is the convolution of the form factor of the particles and the structure factor of the particle distribution. In these conditions, it is possible using a model for the SAXS signal to infer the particle composition and therefore to calculate the precipitate volume fraction in absolute value from the measured integrated intensity. Since the contrast in SAXS arises from the square of the difference in electron density, for simplification $\mathrm{Mg}$ and $\mathrm{Al}\left(\mathrm{Z}_{\mathrm{Mg}}=12\right.$ and $\left.\mathrm{Z}_{\mathrm{Al}}=13\right)$ on one side and $\mathrm{Cu}$ and $\mathrm{Zn}\left(\mathrm{Z}_{\mathrm{Cu}}=29\right.$ and $\left.\mathrm{Z}_{\mathrm{Zn}}=30\right)$ on the other side can be considered to have the same contribution to the electron density. Under this approximation, the electronic contrast can be estimated as arising from a binary system Al-Zn. A low q contribution with a $\mathrm{q}^{-4}$ Porod behaviour has been observed on the SAXS patterns even without artificial ageing. It originates from the Porod asymptotic behaviour from very large features (dispersoids,...) which are much too large to be 
measured by our setup. Its contribution to the measured integrated intensity was always negligible so that we have considered this contribution as a background signal that could be fitted by a contribution proportional to $\mathrm{q}^{-4}$.

The SAXS intensity from the precipitates was considered as arising from a lognormal distribution of spheres. The interference effect was introduced using hard sphere interactions in the PercusYevick approximations [51]. The radius of the hard sphere is assumed proportional to the radius of the precipitates. To speed up the computation, the local monodisperse approximation introduced by Pedersen [52] has been used. Within this approximation, we can write the scattered intensity at scattering vector q:

$$
I(q)=\Delta \rho^{2} \int_{0}^{\infty} F(q, R)^{2} S\left(q, R_{H S}, \varphi\right) N(R) d R
$$

where $\Delta \rho$ is the difference in electron density between the precipitates and the matrix, $F$ is the form factor of the precipitates, $S$ is the structure factor of the precipitate distribution, and $N$ is the precipitate size distribution function. The form factor of a sphere is given by

$$
F(q, R)=4 \pi R^{3} \frac{\sin (q R)-q R \cos (q R)}{(q R)^{3}}
$$

(2)

The lognormal size distribution is described by

$$
N(R)=n_{v} f(R)=n_{v} \frac{1}{\sqrt{2 \pi} R s} e^{-\frac{1}{2 s^{2}} \log \left(R / R_{m}\right)}
$$

with $n_{v}$, the number density of precipitates and $f(R)$, the normalised lognormal distribution of radii ( $R_{m}$ is the median radius and $s$, the dispersion parameter).

$R_{H S}$ is the radius of the hard sphere. We have assumed that it is proportional to $R$, so that

$$
R_{H S}=k R
$$

where the proportionality factor $k$ is comprised between 1 and 2 . We further introduce $f_{v}$, the volume fraction of precipitates.

$$
f_{v}=n_{v} \frac{4}{3} \pi \overline{R^{3}}=n_{v} \frac{4}{3} \pi R_{m}^{3} e^{\frac{9}{2} s^{2}}
$$

From (4), we deduce $\varphi$, the volume fraction of the hard spheres

$$
\varphi=k^{3} f_{v}
$$

The structure factor writes [53] :

$$
S\left(q, R_{H S}, \varphi\right)=\frac{1}{1+24 \varphi \frac{G(A)}{A}}
$$

With $A=2 q R_{H S}$. 


$$
\begin{aligned}
G(A)=\alpha \frac{(\sin A-A \cos A)}{A^{2}}+\beta \frac{\left[2 A \sin A+\left(2-A^{2}\right) \cos A-2\right]}{A^{3}} \\
+\gamma \frac{\left\{-A^{4} \cos A+4\left[\left(3 A^{2}-6\right) \cos A+\left(A^{3}-6 A\right) \sin A+6\right]\right\}}{A^{5}}
\end{aligned}
$$

$$
\begin{gathered}
\alpha=\frac{(1+2 \varphi)^{2}}{(1-\varphi)^{4}} \\
\beta=\frac{-6 \varphi\left(1+\frac{\varphi}{2}\right)^{2}}{(1-\varphi)^{2}} \\
\gamma=\varphi \frac{\alpha}{2}
\end{gathered}
$$

(9)

Within our assumptions on the composition and since we are far from any absorption edge, we have:

$$
\Delta \rho^{2}=C_{Z n}^{2}\left(\frac{f_{Z n}-f_{A l}}{\Omega}\right)^{2}
$$

where $f_{\mathrm{Zn}}$ and $f_{A l}$ are respectively the scattering factors of $\mathrm{Zn}$ and $\mathrm{Al}, \Omega$ is the atomic volume and $\mathrm{C}_{\mathrm{Zn}}$ is the $\mathrm{Zn}$ atom fraction in the precipitates (neglecting that of the matrix). Finally, the intensity writes:

$$
I(q)=f_{v} C_{Z n}^{2}\left(\frac{f_{Z n}-f_{A l}}{\Omega}\right)^{2} \int_{0}^{\infty} F(q, R)^{2} S\left(q, k R, f_{v}\right) \frac{f(R)}{\frac{4}{3} \pi \overline{R^{3}}} d R
$$

Equation (11) shows that the volume fraction appears both in the pre-factor, which in a sense scales the intensity, and in the structure factor from which originates the interference peak. Within the "scale factor" alone, $f_{v}$ and $C_{Z n}{ }^{2}$ cannot be separated so that it is only when enough information about the shape of the interference peak is contained in the data that the composition of the precipitates can be extracted. Therefore, we first studied the early stages of precipitation when the interference peak is clearly resolved in order to deduce a more general form of the evolution of the precipitate composition that could be used for the rest of the study.

The size distribution is described by a median radius $R_{m}$ and a dispersion factor $s$. In order to show a single value that is relevant to small angle scattering, we have chosen to represent the size evolution by the Guinier radius, which can be recalculated from the lognormal distribution:

$$
\begin{gathered}
R_{g}{ }^{2}=\frac{3}{5} \overline{\overline{R^{8}}} \\
R_{g}=\sqrt{\frac{3}{5}} R_{m} e^{7 s^{2}}
\end{gathered}
$$

This Guinier radius has been shown to be close to the average radius for values of s close to $20 \%$ [48]. 
On figure 1(b), the result of the fitting process has been plotted during a ramp heating of the $\mathrm{ST}+\mathrm{NA}$ initial state at $0.5 \mathrm{~K} / \mathrm{min}$. The volume fraction is shown to first decrease at constant $\mathrm{Zn}$ composition at about 36\%. At some stage during the dissolution, the $\mathrm{Zn}$ content of the precipitates is observed to grow, indicating a possible phase transition from GP zones to more stable precipitates like $\eta$ ' and $\eta$. This transition occurs simultaneously to an increase of the precipitate size. SAXS patterns corresponding to 3 different times in the kinetics (highlighted by colour dots on figure 1(b)) are shown on figure 1(a), together with the fitted intensity. It can be deduced from these curves that the interference peak is well defined during the GP zones stage and the beginning of the phase transition, so that the fitted $\mathrm{Zn}$ composition can be determined with good confidence. In the subsequent stages, when the volume fraction decreases simultaneously to an increase of size, the amplitude of the peak becomes too small to provide enough information (material at $90^{\circ} \mathrm{C}$ ). Furthermore, it will be shown further in the paper that to interpret the HPT-processed sample, a second population of precipitates will be necessary, lowering even more the probability of resolving the interference peak. For the remaining of the study, and based on the results of figure 1, we have assumed that $\mathrm{Zn}$ composition of the GP zones is constant at $36 \%$ and we have fixed a maximal $\mathrm{Zn}$ composition for the $\eta$ ' / $\eta$ phase at 53\%, corresponding to the results from Marlaud and co-workers [42]. To allow for a smooth transition from one phase to the other, we have assumed that the composition is related to the size of the precipitates, evolving from $36 \%$ to $53 \%$ via a step function (erf) at a critical size of $0.9 \mathrm{~nm}$. It should be noted that the spherical shape assumption may not be the best model for the $\eta$ ' / $\eta$ phase, however we do believe that this assumption does not influence the trend in terms of size, nor the estimation of the volume fraction (as the latter originates essentially from an integration of the signal). This model was then applied to all in-situ data during the heat treatments.

Now that the SAXS intensity evolution has been adequately modelled, we can turn back to the precipitate evolution during ramp heating at $0.5 \mathrm{~K} \cdot \mathrm{min}^{-1}$. A few scattering curves are shown along this heat treatment in figure 2 in a Kratky plot. In such a plot a peak corresponds to the presence of a precipitate size distribution. The position of the peak (in value of $q$ ) is inversely proportional to the mean precipitate size, and the area under the peak is proportional to the product of the precipitate volume fraction and the square of the contrast in electron density between the precipitates and matrix [37]. At first (here between the initial state and the signal at $100^{\circ} \mathrm{C}$ ), the signal is observed to decrease, corresponding to a decrease of volume fraction without much change in q-range and thus of precipitate size. At higher temperature, the signal translates to much smaller scattering vectors, reflecting an increasing precipitate size. This can be evaluated more quantitatively by using the intensity model introduced earlier. The evolution of precipitate size and volume fraction during the ramp heat treatment are shown in figure 2(b). When the temperature reaches about $60^{\circ} \mathrm{C}$, the volume fraction starts to decrease. The precipitate radius is very stable almost until the end of the precipitate reversion that happens at about $110^{\circ} \mathrm{C}$. Subsequently, the radius and volume fraction suddenly increase together. This corresponds to the increase of $\mathrm{Zn}$ content discussed earlier and can therefore be associated to the formation of the more stable $\eta$ ' phase. When the temperature reaches about $180^{\circ} \mathrm{C}$, the volume fraction saturates at about $2.5 \%$ and starts to decrease again while the precipitate size continues to increase regularly. This decrease in volume fraction is an experimental artefact arising from the fact that an increasing fraction of the scattered intensity is lost into the beam-stop when precipitates become too large.

In the following we present the precipitation kinetics in two isothermal situations at 70 and $100^{\circ} \mathrm{C}$. $70^{\circ} \mathrm{C}$ is a temperature where, during ramp heating, reversion is still moderate and nucleation of $\eta$ ' has not started yet. At $100^{\circ} \mathrm{C}$ during ramp heating, the reversion is nearly complete and nucleation of $\eta$ ' is merely starting. Figure 3 shows the evolution of the SAXS signal during isothermal heating for $40 \mathrm{~h}$ at the two temperatures. The evolution of precipitates is very different at the two temperatures. At $70^{\circ} \mathrm{C}$, the microstructural evolution is very gradual and the signal hardly shifts to smaller scattering vectors, which means that the precipitate size increase is moderate. At $100^{\circ} \mathrm{C}$, the signal evolves as soon as the temperature is reached and then much more strongly. The 
quantification of this evolution is shown in figure 4 . At $70^{\circ} \mathrm{C}$, a progressive reversion is observed, to end up after 40 to $50 \mathrm{~h}$ with a volume fraction of precipitates half of the initial one. The precipitate radius only increases from 0.8 to $1.2 \mathrm{~nm}$ in this time interval. It is impossible to ascertain if the phase transformation from GP zones to $\eta$ ' has occurred, but if it has, it is at most partial. At $100^{\circ} \mathrm{C}$, however, the reversion is very rapid (as was observed during ramp heating) and it is followed by a sharp transition to the $\eta$ ' phase with a rapid increase of volume fraction and precipitate size.

\section{Precipitation kinetics in the severely deformed material}

Figure 5 shows the comparison of the SAXS signals for the solution treated and naturally aged (ST+NA) and HPT-processed and naturally aged (HPT+NA) samples both in a log-log plot and in a Kratky plot. In both materials the signal is dominated by objects of very small size (radius less than $1 \mathrm{~nm}$ ) that can be identified as GP zones. Their volume fraction (in first approximation the area under the Kratky plot) is similar in the two materials and their size (in first approximation inversely proportional to the position in scattering vector of the maximum of I.q ${ }^{2}$ ) is slightly smaller in the HPT-processed material. The log-log plot shows that the signal at very small angles of the HPTprocessed material contains a stronger contribution as compared to the ST+NA material, in the form of a power law close to $q^{-2.5}$. Such a contribution arises probably from the microstrain present after severe plastic deformation [54] however its contribution to the integrated intensity of the Kratky plot is negligible. Thus for all practical purposes the two initial microstructures are observed to be essentially similar.

Figure 6 presents Kratky plots of the SAXS signals at characteristic stages during the three heat treatments investigated (namely, ramp heating at $0.5 \mathrm{~K} \cdot \mathrm{min}^{-1}$, isothermal heat treatment at $70^{\circ} \mathrm{C}$ and isothermal heat treatment at $100^{\circ} \mathrm{C}$ ). In all three cases one observes a very different evolution of the signal as compared to that of the ST+NA material (one SAXS curve from this material is represented for comparison). In the conventionally processed material, the whole scattering curve was observed to shift progressively towards smaller scattering vectors, reflecting that the precipitate size distribution remained mostly self-similar. In the HPT-processed material, however, a new signal at very small angles appears rapidly in addition to the still existing signal at large angles, reflecting the formation of large particles (of radius about $3 \mathrm{~nm}$ ) simultaneously to the existence of small ones that are still similar to the GP zones initially present (of radius smaller than $1 \mathrm{~nm}$ ). With time, the presence of the large particles becomes more prominent and the GP zones tend to disappear. This behaviour is more pronounced as temperature becomes higher. During ramp heating the first indication of large precipitates formation is observed at about $80^{\circ} \mathrm{C}$. During the isothermal heat treatment at $70^{\circ} \mathrm{C}$, the formation of these large precipitates occurs in a few hours, although it was observed that phase transformation to $\eta / \eta$ at $70^{\circ} \mathrm{C}$ was very slow in the conventionally processed material. At $100^{\circ} \mathrm{C}$ during the ramp heating experiment, the process of formation of these large particles is already well advanced, so that it is no surprise to observe that in less than one hour at this temperature during isothermal heat treatment the large precipitates have practically overcome the small ones. Again, as exemplified by the SAXS signal for similar heat treatment, in the conventionally processed material the evolution is much slower and there is no evidence of a bimodal precipitate size distribution.

The next step is to quantify these two precipitate populations so that it becomes possible to separate their respective contributions. For that purpose the following hypothesis are made:

- The small particles are similar to that present in the conventionally processed material. Therefore the same rule is followed for their composition in solute, namely $36 \% \mathrm{Zn}$ in the initial state and an evolving composition to $53 \% \mathrm{Zn}$ when their size is larger that $0.9 \mathrm{~nm}$. 
- A second population of precipitates is also considered with the same rule governing their composition. However, as the results will show, their size is always above $1 \mathrm{~nm}$ so that they appear directly with a composition of equilibrium particles, that we assume being 53\%Zn.

Then the SAXS signal is adjusted to a model containing these two precipitate families, which are both considered spherical, with lognormal size distribution.

Figure 7 shows the evolution of the size and volume fraction of both precipitates families during ramp heating at $0.5 \mathrm{~K} \cdot \mathrm{min}^{-1}$. The evolution of precipitates in the ST+NA material is also shown for comparison. As noted qualitatively in the Kratky plots of figure 6(a), the large precipitates that have initially a negligible volume fraction (notice the log scale) start to form significantly at $80^{\circ} \mathrm{C}$, and then their volume fraction, together with their size, increases rapidly until $120^{\circ} \mathrm{C}$. The subsequent decrease of volume fraction is undoubtedly related to the loss of SAXS signal into the beam stop because of a too large precipitate size. The behaviour of the small particles (initially GP zones) is particularly interesting. They are present in a somewhat lower fraction as in the ST+NA sample, but then experience a very similar evolution, namely a reversion in the same temperature range, at a similar rate relative to the initial volume fraction and with an almost identical evolution in radius. The evolution of the small precipitate family of the HPT-processed material only deviates strongly from that of the ST+NA material at relatively high temperatures (above $140^{\circ} \mathrm{C}$ ) when the large precipitates have become dominant in the microstructure.

Now isothermal heat treatments will be investigated to see if similar conclusions can be drawn. Figure 8 shows the evolution of the two precipitate families during the $70^{\circ} \mathrm{C}$ heat treatment. In agreement with the qualitative conclusions drawn from the Kratky plots (figure 6(b)), the large precipitates grow significantly in a few hours; however in contrast with the ramp heating experiment, their volume fraction does not become larger than that of the small precipitates in the investigated time range (50h). Their size is comparable to the size of the large precipitates formed during ramp heating. It is representative of the size of precipitates that would form during heat treatment of conventionally processed materials at much higher temperature: for similar alloys, it takes several hours at $160^{\circ} \mathrm{C}$ to reach such sizes (see e.g. [42]). As for the small precipitates (initially GP zones), their behaviour strikingly resembles that of the ST+NA sample, shifted to a slightly smaller volume fraction. The reversion rate is remarkably similar in the two materials, and the radius evolution is nearly identical.

The evolution during heat treatment at $100^{\circ} \mathrm{C}$ is shown in figure 9. Consistently with the Kratky plots of figure 6(c), the formation of large precipitates is very rapid. Their volume fraction becomes larger than that of the small precipitates in about $1 \mathrm{~h}$, and then slowly decreases certainly because their size becomes too large for the SAXS measurement. As for the small precipitates, again their behaviour is very similar to that of the ST+NA material. The extent of reversion in the HPT material is larger, but happens with the same kinetics, and the evolution of precipitate size is almost identical in the two materials.

\section{Electron microscopy observations of the microstructure in the severely processed material}

The quantitative evaluation of precipitation kinetics provided by the in-situ SAXS measurements presented above has been supplemented by observations with electron microscopy. Figure 10(a) shows a bright-field micrograph of the microstructure in the material after HPT processing and natural ageing. Classically for high solute content $\mathrm{Al}$ alloys processed in similar conditions, the microstructure shows a very small scale, although it is difficult to precisely separate the different origins of contrast (small grain size, high dislocation density, internal stresses). The magnitude of the grain size can be better evaluated from the orientation maps as show in figure 11(a). It is of the order of $100 \mathrm{~nm}$. As for precipitates present in this initial state, given the high contrast due to crystal defects and the very small size of GP zones, these cannot be resolved in the bright-field micrograph. 
Figure 10(b) and (c) show a dark-field and a bright-field micrographs of the alloy aged 48h at $100^{\circ} \mathrm{C}$. In this case, the contrast is quite lower, showing qualitatively a reduction in the amount of crystalline defects present. Now precipitates can be readily observed. Very clearly the precipitate distribution is bi-modal. At the core of the grains, extremely fine precipitates can be observed. These correspond to the small precipitates measured during the SAXS experiments. On the grain boundaries and at other crystalline defects, much larger precipitates are observed. At this ageing time, the radius of the largest ones can reach $30 \mathrm{~nm}$, which is clearly out of the measuring range of our SAXS measurements. However these were certainly the precipitates measured with a radius of 4 to $6 \mathrm{~nm}$ during the first hours at $100^{\circ} \mathrm{C}$. In terms of grain size, figure 11 (c) shows the grain microstructure after the same ageing treatment obtained from the orientation map. Clearly the grain size has significantly increased in comparison to the HPT+NA state. This is further confirmed by the comparison of the selected area electron diffraction patterns of the HPT+NA and $100^{\circ} \mathrm{C}$ aged material (figure 10(d)); the diffraction pattern is initially characteristic of a very small grain size and high density of defects with almost continuous diffraction rings. After ageing at $100^{\circ} \mathrm{C}$ the rings become much more punctuated, reflecting the decrease in internal microstrains and increase in grain size. From figure $11(\mathrm{~b})$, showing an orientation map of the material aged at $70^{\circ} \mathrm{C}$ for $48 \mathrm{~h}$, we can conclude that no significant grain growth has occurred.

\section{Resulting hardness evolution}

Finally, the evolution of the material's microhardness has been evaluated after HPT and natural ageing, as well as during isothermal ageing at $70^{\circ} \mathrm{C}$ and $100^{\circ} \mathrm{C}$ (Figure 12). Data obtained on the conventionally processed material was gathered in the same conditions for comparison.

In the conventionally processed material, natural ageing after solution treatment increases the hardness to about $150 \mathrm{HV}$. Artificial ageing provides an additional hardening, which occurs faster at $100^{\circ} \mathrm{C}$ as compared to $70^{\circ} \mathrm{C}$, consistently with the appearance of the $\eta$ ' phase.

The HPT-processed material shows already a very high hardness of about $210 \mathrm{HV}$. After natural ageing this hardness reaches $240-250 \mathrm{HV}$, thanks to the combination of the small grain size, high density of crystalline defects and presence of GP zones. When the naturally aged material is aged at $70^{\circ} \mathrm{C}$, the hardness is stable and even slightly increases over $250 \mathrm{HV}$. At $100^{\circ} \mathrm{C}$, however, the hardness is initially stable and the slowly decreases to reach $230 \mathrm{HV}$ at the end of the heat treatment.

\section{Discussion}

The present study provides to our knowledge the first quantitative evaluation of the kinetics of precipitate evolution during ageing following severe plastic deformation through HPT processing. It provides conclusive evidence on several points that will now be discussed.

The first interesting feature concerns the initial states before artificial ageing, namely the naturally aged materials after either conventional processing (ST+NA) or HPT processing (HPT+NA). The SAXS results show that the two microstructures are very similar. The HPT-processed material, after several months at room temperature, does not show any significant presence of coarse equilibrium precipitates, in contrast to what has been observed in binary $\mathrm{Al}-\mathrm{Cu}$ [12] where the equilibrium phase $\theta$ forms at room temperature after SPD. However this lack of coarse precipitation at room temperature is consistent with former published data on 7000 series $\mathrm{Al}$ alloys [29]. This strong difference between the two alloy series is yet to be explained, and may be due to the combination of differences in vacancy-solute interactions, nucleation mechanisms and interfacial energies. Secondly, the two initial states contain a similar GP zone microstructure, both in terms of size and of volume fraction. Following the hardness evolution during natural ageing, it is observed that right after HPT processing the hardness is already very high $(>200 \mathrm{HV})$. This strongly suggests that the formation of most of the GP zones has occurred extensively during HPT processing by dynamic 
precipitation and that the subsequent evolution of the GP zone fraction is only moderate. The fraction of GP zones in our two initial states certainly is simply the equilibrium fraction at room temperature (accounting for the Gibbs-Thomson effect associated to the very small size of the particles).

When the conventionally processed material is aged, a change in precipitate composition is observed to occur progressively, controlled by the precipitate size and thus indirectly by the sample temperature. This transition is very slow at $70^{\circ} \mathrm{C}$, rapid at $100^{\circ} \mathrm{C}$ and occurs from $80^{\circ} \mathrm{C}$ onwards during ramp heating at $0.5 \mathrm{~K} \cdot \mathrm{min}^{-1}$. It is correlated to the evolution of precipitate size, and it can be reasonably related to the transition between GP zones and more stable phases ( $\eta$ ', $\eta)$.

In the HPT-processed material, the precipitation kinetics is more complicated. Larger precipitates (nucleation radius of the order of $3 \mathrm{~nm}$ ) are observed to appear at temperatures as low as $70^{\circ} \mathrm{C}$, where precipitates in the conventionally processed material evolve only very slowly and remain at a small size. These precipitates grow fast and at $100^{\circ} \mathrm{C}$ or during ramp heating are observed to dominate the microstructure. The accelerated formation of coarse precipitates is consistent with the existing literature [6,29] and our contribution is mainly to assess the temperature at which this precipitation can be activated. Although they do not form at room temperature in the time scale investigated here (several months), we have shown that their nucleation can be activated during a few hours at a temperature as low as $70^{\circ} \mathrm{C}$. From the electron microscopy observations, it can be inferred that these precipitates form on the structural defects created by the HPT process (grain boundaries and dislocations).

The really interesting feature is however the behaviour of the small precipitates initially present in the HPT-processed material (the GP zones). These small precipitates are observed to evolve during artificial ageing in a manner extremely similar to their counterparts in the conventionally processed material. This similarity applies to the kinetics (like the time for the maximum extent of reversion) and to the quantitative evolution (like the growth rate of the precipitates). The electron microscopy observations show that these small precipitates are located in the regions, which are far from structural defects. It has been shown [55] that the kinetics of reversion is very sensitive to the diffusion rate of solutes independently of other parameters of the precipitation system. In fact the time for a given amount of reversion is directly proportional to the diffusion coefficient, all other parameters being equal. Therefore it can be expected that the diffusion coefficient in the grain interior of the severely plastically deformed material is similar to that of the conventionally processed material. A close look at figure 7 reveals a temperature difference of only $4 \mathrm{~K}$ for the minimum of volume fraction detected during reversion between the ST+NA and HPT+NA materials. If we consider a range of activation energies for bulk diffusion of 1 to $1.5 \mathrm{eV}$, this $4 \mathrm{~K}$ temperature difference translates into a difference of 30 to $40 \%$ only in diffusion constant. This reveals that the vacancy concentration is almost the same in the two materials (HPT+NA and ST+NA). We believe that this is the first (indirect) evidence of similar vacancy concentration in an SPD precipitation hardening $\mathrm{Al}$ alloy as compared to its coarse grain counterpart. It contrasts with some estimations that the vacancy concentration in SPD materials may be many orders of magnitude larger than in the coarse grained materials [12,34,36]. However, the materials evaluated in our study were naturally aged for several months before the ageing treatments were realised. It may be that high excess vacancy concentrations did exist during or immediately after HPT processing, and that these excess vacancies did not survive after natural ageing. However, the state of GP zone development in the HPT+NA and ST+NA materials is similar, which means that possible differences in vacancy concentrations did not profoundly change the microstructure once a stable microstructure at room temperature is reached.

In preceding studies, the high vacancy concentrations have been associated with the formation at low temperature of large, equilibrium phases. Such particles have been observed in the present study, forming during artificial ageing where it has been shown that the vacancy concentration was equal to that of the conventionally processed alloy. Therefore, an alternative mechanism needs to be 
invoked to explain their accelerated formation. Actually, our observations of grain size evolution by automated crystal orientation mapping show that the grain size significantly evolves, at least at $100^{\circ} \mathrm{C}$ where the coarse precipitates are observed to form particularly rapidly. Since the coarse precipitates have been shown to be associated with the structural defects, it seems very likely that the migration of these defects during heat treatment is closely associated to the formation of these precipitates. Former studies have actually shown that precipitate formation and decrease of microstrain and dislocation density were highly correlated during ageing of SPD processed 7xxx alloys [29]. The solute collector mechanism has already been invoked before to account for the acceleration of precipitation kinetics in SPD materials [12]. And a recent study of mixing different materials by HPT processing [35] has shown that the diffusion rate necessary to account for the kinetics of mixing was compatible with surface precipitation, which further demonstrates the importance of diffusion at the interfaces and supports the hypothesis of structural defect migration to account for the accelerated precipitation kinetics in our study.

\section{Summary and Conclusions}

In this paper we have reported a quantitative study, using small-angle X-ray scattering (SAXS), of the precipitation kinetics in an AA7075 Aluminium alloy processed by high-pressure torsion (HPT) at room temperature. This precipitation kinetics has been compared with that of the same material processed in a conventional manner. The SAXS measurements have been carried out in-situ during a continuous heating experiment at $0.5 \mathrm{~K} \cdot \mathrm{min}^{-1}$ and during isothermal ageing at $70^{\circ} \mathrm{C}$ and $100^{\circ} \mathrm{C}$. Additionally transmission electron microscopy has been carried out to obtain a qualitative view of the precipitate distribution after ageing and to characterise the material's grain size using automated crystal orientation mapping. From these results the following conclusions can be proposed:

- After HPT followed by several months of natural ageing the material contains a similar GP zone microstructure as compared to the conventionally processed material. No sign of the presence of coarse precipitates is detected at this stage.

- When temperature is increased in the HPT-processed material, extensive coarse precipitation occurs at low temperature. The time necessary to obtain such coarse precipitates is considerably shorter than in the conventionally processed material. These precipitates are related to the crystalline defects present initially, and it is likely that the presence of these defects, and possibly their migration, during ageing plays a key role in the solute transport involved in their formation.

- Conversely, fine scale precipitates remain at the core of the nano-grains during the first stages of the formation of these coarse precipitates. These fine scale precipitates respond to temperature changes exactly in the same way as in the conventionally processed materials. From this result, it can be inferred that the vacancy concentration at the core of the nanograins is similar to that of the conventionally processed material.

- From a more practical viewpoint, artificial ageing at low temperatures (here $70^{\circ} \mathrm{C}$ ) makes it possible to further increase the strength from the SPD processed state, due to the extensive precipitation with limited coarsening associated with the retention of the small grain size.

\section{Acknowledgements}

This research was supported in part by Japan Science and Technology Agency (JST) under Collaborative Research Based on Industrial Demand "Heterogeneous Structure Control: Towards Innovative Development of Metallic Structural Materials", in part by the Light Metals Educational Foundation of Japan, in part by a Grant-in-Aid for Scientific Research from the MEXT, Japan, in innovative Areas "Bulk Nanostructured Metals" (22102004). 


\section{References}

[1] Valiev R., Islamgaliev R., Alexandrov I. Prog. Mater. Sci. 2000;45:103.

[2] Valiev RZ, Langdon TG. Prog. Mater. Sci. 2006;51:881.

[3] Zhilyaev AP, Langdon TG. Prog. Mater. Sci. 2008;53:893.

[4] Chinh NQ, Gubicza J, Czeppe T, Lendvai J, Xu C, Valiev RZ, Langdon JG. Mat. Sci. Eng. A 2009;516:248.

[5] Duan ZC, Liao XZ, Kawasaki M, Figueiredo RB, Langdon TG. J. Mat. Sci. 2010;45:4621.

[6] Ghosh KS, Gao N, Starink MJ. Mat. Sci. Eng. A 2012;552:164.

[7] Krishna KG, Sivaprasad K, Venkateswarlu K, Kumar KCH. Mat. Sci. Eng. A 2012;535:129.

[8] Gubicza J, Schiller I, Chinh NQ, Illy J, Horita Z, Langdon TG. Mat. Sci. Eng. A 2007;460-461:77.

[9] Han J-H. Mater Trans 2010;51:2109.

[10] Hockauf K, Meyer LW, Hockauf M, Halle T. J. Mat. Sci. 2010;45:4754.

[11] Horita Z, Ohashi K, Fujita T, Kaneko K, Langdon TG. Adv. Mater. 2005;17:1599.

[12] Huang Y, Robson JD, Prangnell PB. Acta Mater. 2010;58:1643.

[13] Cabibbo M. Mat. Charact. 2012;68:7.

[14] Cabibbo M, Evangelista E, Vedani M. Met. Mater. Trans. A 2005;36A:1353.

[15] Cardoso KR, Travessa DN, Botta WJ, Jorge AM. Mat. Sci. Eng. A 2011;528:5804.

[16] Cepeda-Jimenez CM, Garcia-Infanta JM, Zhilyaev AP, Ruano OA, Carreno F. J. Alloys Comp. 2011;509:636.

[17] Cerri E, Leo P. Mat. Sci. Eng. A 2005;410:226.

[18] Huang W, Liu Z, Lin M, Zhou X, Zhao L, Ning A, Zeng S. Mat. Sci. Eng. A 2012;546:26.

[19] Lee S, Horita Z, Hirosawa S, Matsuda K. Mat. Sci. Eng. A 2012;546:82.

[20] Liu Z, Bai S, Zhou X, Gu Y. Mat. Sci. Eng. A 2011;528:2217.

[21] Munoz-Morris MA, Morris DG. Mat. Sci. Eng. A 2011;528:3445.

[22] Murayama M, Horita Z, Hono K. Acta Mater. 2001;49:21.

[23] Roven HJ, Liu M, Werenskiold JC. Mat. Sci. Eng. A 2008;483-84:54.

[24] Sha G, Wang YB, Liao XZ, Duan ZC, Ringer SP, Langdon TG. Acta Mater. 2009;57:3123.

[25] Tsai M-S, Sun P-L, Kao P-W, Chang C-P. Mater. Trans. 2009;50:771.

[26] Tsuji N, Iwata T, Sato M, Fujimoto S, Minamino Y. Sci. Tech. Adv. Mater. 2004;5:173.

[27] Xu C, Furukawa M, Horita Z, Langdon TG. Acta Mater. 2003;51:6139.

[28] Zhang J, Gao N, Starink MJ. Mat. Sci. Eng. A 2010;527:3472.

[29] Zhao YH, Liao XZ, Jin Z, Valiev RZ, Zhu YT. Acta Mater. 2004;52:4589.

[30] Straumal B., Baretzky B, Mazilkin A., Phillipp F, Kogtenkova O., Volkov M., Valiev R. Acta Mater. 2004;52:4469.

[31] Hu T, Ma K, Topping TD, Schoenung JM, Lavernia EJ. Acta Mater. 2013;61:2163.

[32] Liddicoat PV, Liao X-Z, Zhao Y, Zhu Y, Murashkin MY, Lavernia EJ, Valiev RZ, Ringer SP. Nature Comm. 2010;1.

[33] Hirosawa S, Hamaoka T, Horita Z, Lee S, Matsuda K, Terada D. Met. Mater. Trans. A 2013;44A:3921.

[34] Sauvage X, Wetscher F, Pareige P. Acta Mater. 2005;53:2127.

[35] Oh-ishi K, Edalati K, Kim HS, Hono K, Horita Z. Acta Mater. 2013;61:3482.

[36] Lechner W, Puff W, Mingler B, Zehetbauer MJ, Wuerschum R. Scripta Mater. 2009;61:383.

[37] De Geuser F, Deschamps A. C. R. Phys. 2012;13:246.

[38] Deschamps A, De Geuser F. Met. Mater. Trans. A 2013;44A:77.

[39] Malard B, Remy B, Scott C, Deschamps A, Chene J, Dieudonne T, Mathon MH. Mat. Sci. Eng. A 2012;536:110.

[40] Nicolas M, Deschamps A. Acta Mater. 2003;51:6077.

[41] Dumont M, Steuwer A, Deschamps A, Peel M, Withers PJ. Acta Mater. 2006;54:4793.

[42] Marlaud T, Deschamps A, Bley F, Lefebvre W, Baroux B. Acta Mater. 2010;58:248. 
[43] Bakavos D, Prangnell P, Bes B, Eberl F, Grossmann J. Mat. Sci. Forum 2006;519-521:333.

[44] Kenesei P, Horvath G, Bernstorff S, Ungar T, Lendvai J. Zeit. Metallk. 2006;97:315.

[45] Horita Z, Fujinami T, Nemoto M, Langdon TG. Met. Mater. Trans. A 2000;31:691.

[46] Zhang F, llavsky J, Long GG, Quintana JPG, Allen AJ, Jemian PR. Met. Mater. Trans. A 2010;41A:1151.

[47] Rauch EF, Veron M. Mater. Werkst. 2005;36:552.

[48] Deschamps A, De Geuser F. J. Appl. Crystallogr. 2011;44:343.

[49] Sha G, Cerezo A. Acta Mater. 2004;52:4503.

[50] Zhao Y-H, Liao X-Z, Cheng S, Ma E, Zhu YT. Adv. Mater. 2006;18:2280.

[51] Vrij A. J. Chem. Phys. 1979;71:3267.

[52] Pedersen JS. J. Appl. Crystallogr. 1994;27:595.

[53] Kinning D, Thomas E. Macromolecules 1984;17:1712.

[54] Epperson J, Loomis B, Lin J. J. Nucl. Mater. 1982;108:476.

[55] Deschamps A, Perez M. C. R. Phys. 2010;11:236. 

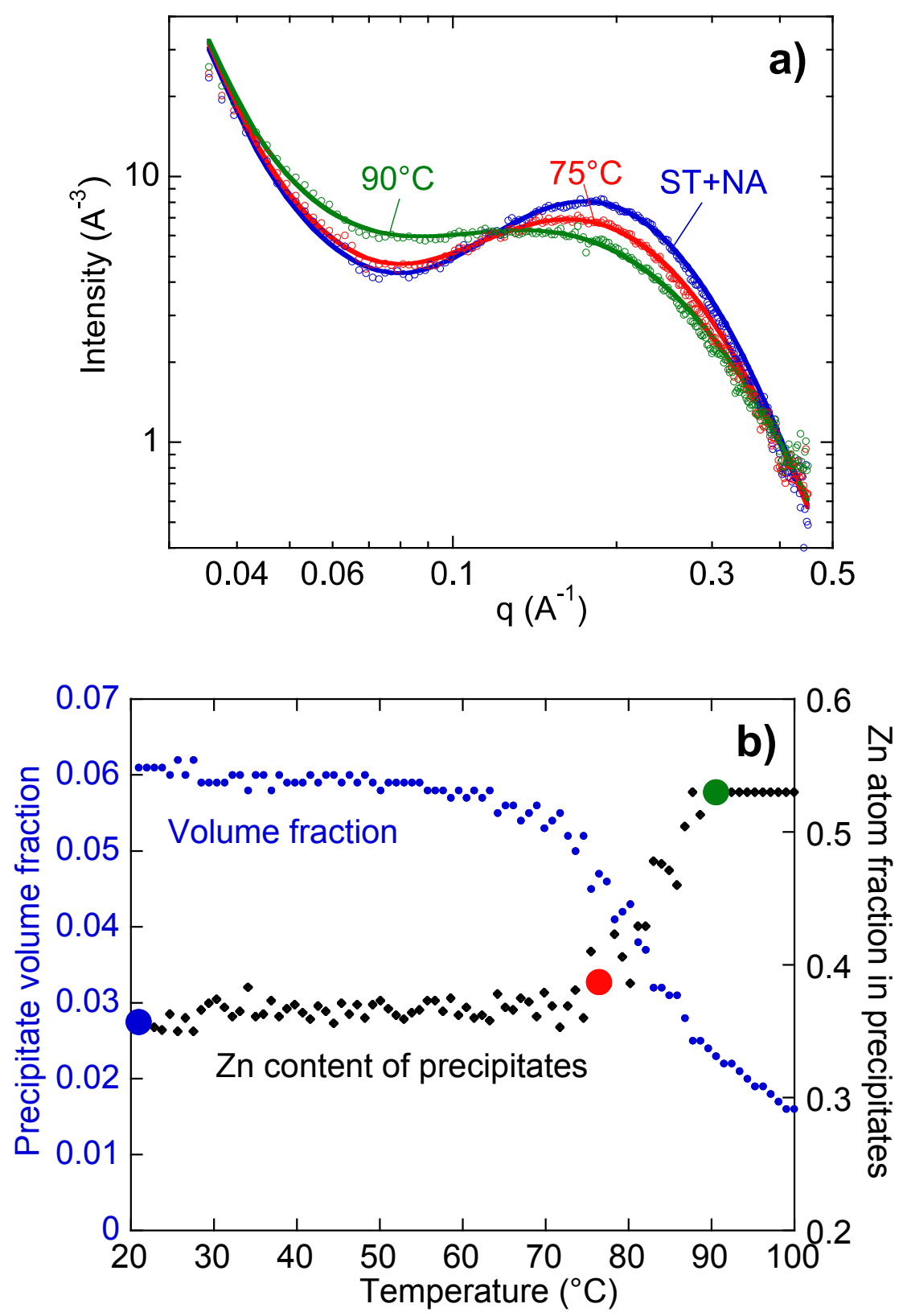

Figure 1: (a) Log-log plot of the SAXS intensity, along with the modelled signal, in the initial state of the conventional grain size material (ST+NA) and at two stages of the ramp heat treatment defined with respect to the evolution of volume fraction in (b). 

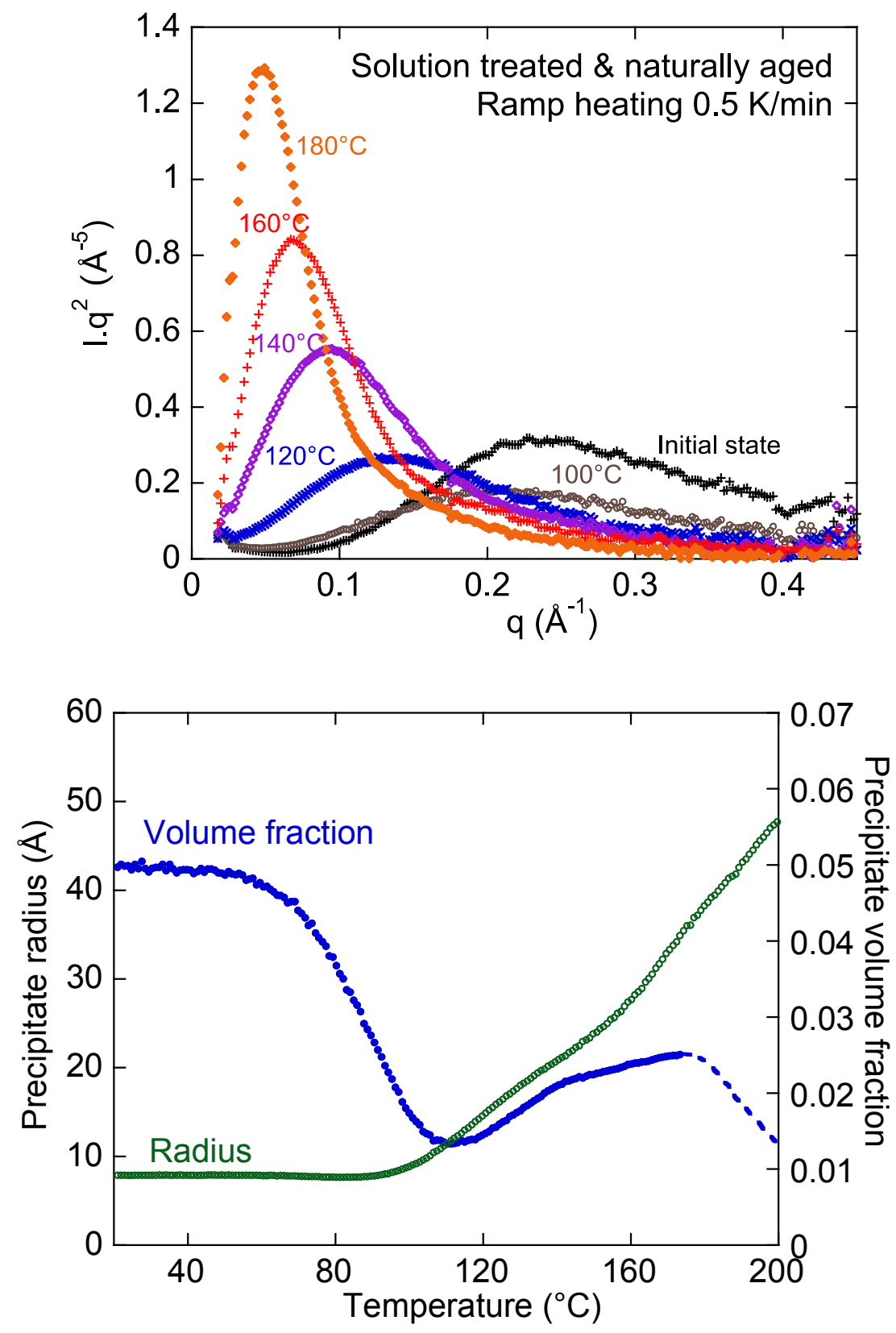

Figure 2: (a) Kratky plot of the SAXS signal during the heating ramp at $0.5 \mathrm{~K} / \mathrm{min}$ performed on the ST\&NA material. (b) Evolution of volume fraction, average radius and precipitate composition calculated from this data along the same heat treatment (the dashed line corresponds to data where a significant fraction of the SAXS data is lost into the beamstop). 


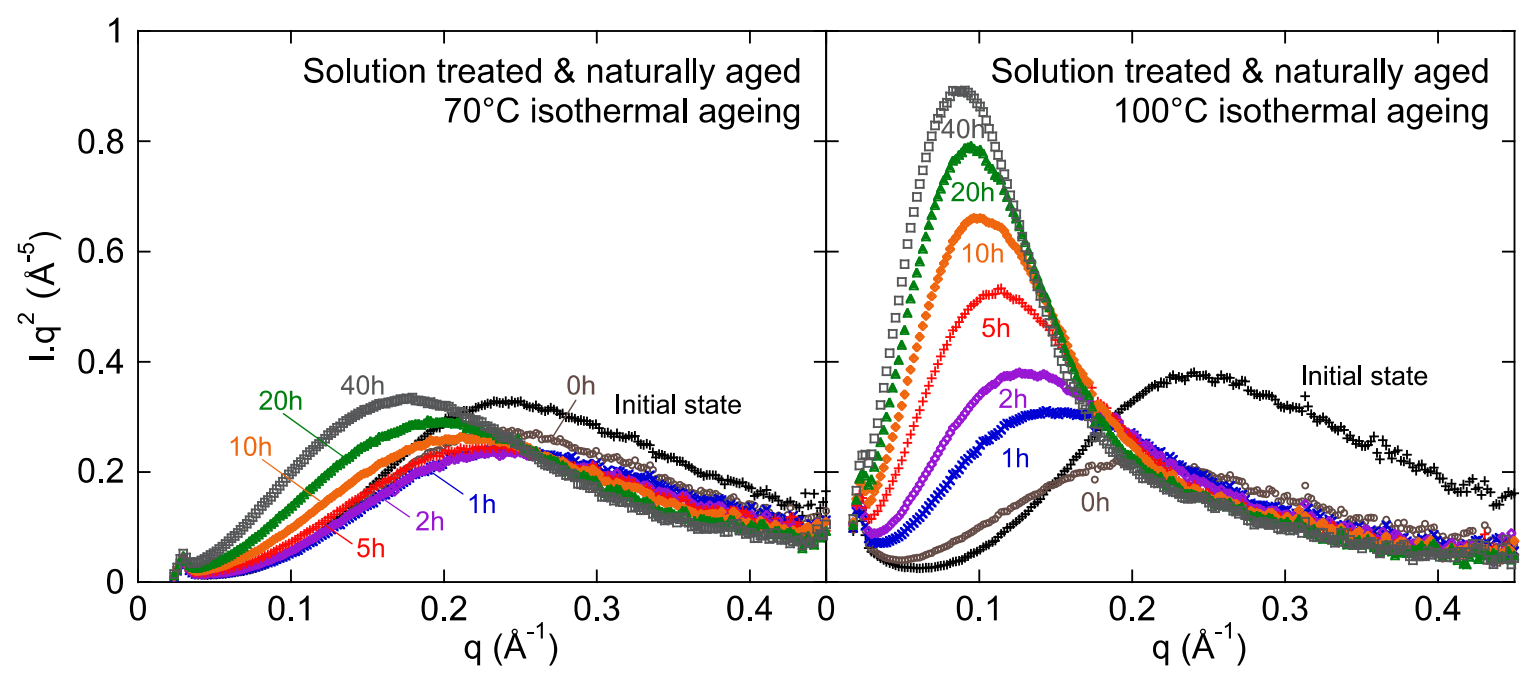

Figure 3: Kratky plot of the SAXS signal during the isothermal heat treatment performed on the ST\&NA material at (a) $70^{\circ} \mathrm{C}$ and (b) $100^{\circ} \mathrm{C}$. 


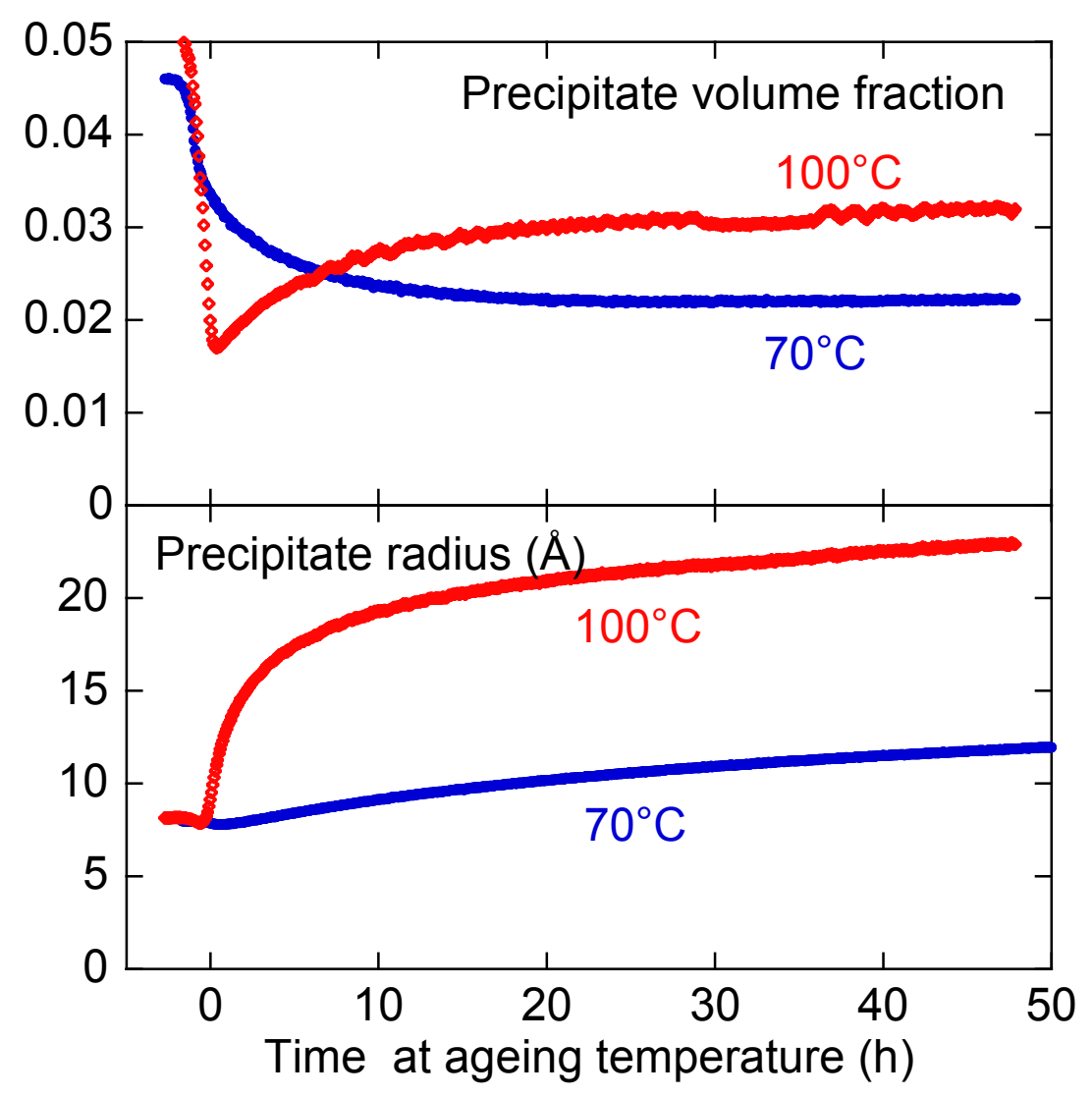

Figure 4: Evolution of volume fraction and average precipitate radius during isothermal heat treatments at $70^{\circ} \mathrm{C}$ and $100^{\circ} \mathrm{C}$ performed on the ST\&NA material.
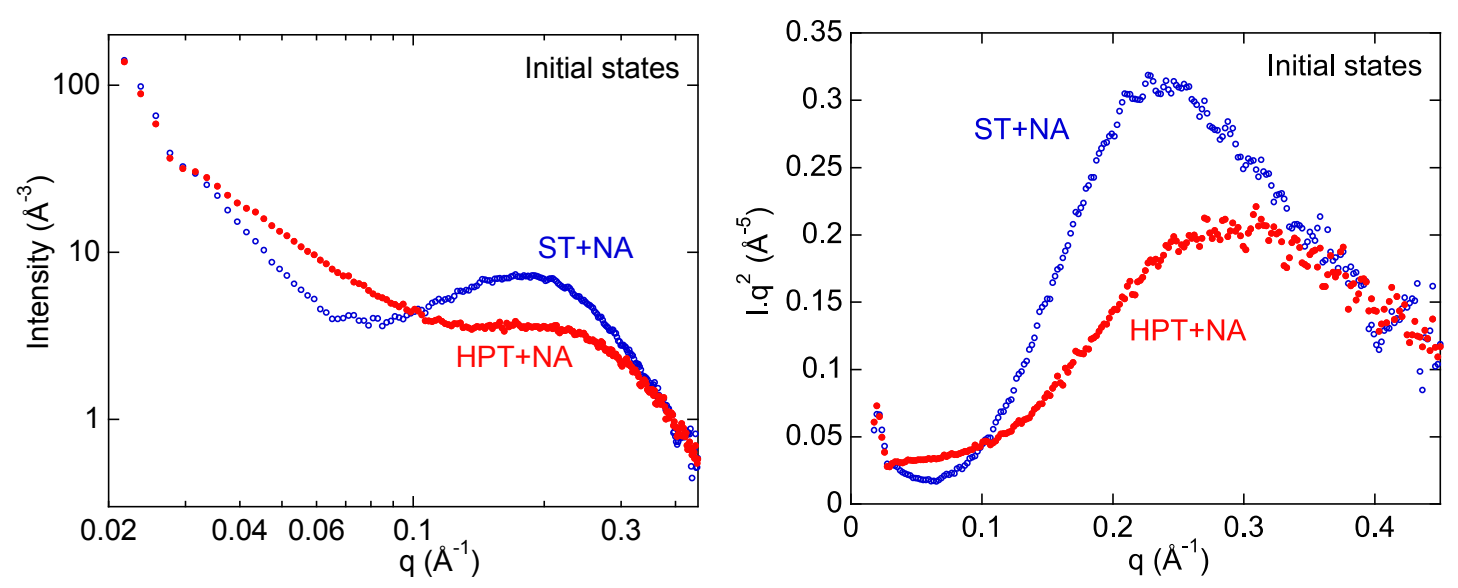

Figure 5: Log-log and Kratky plot of the SAXS signal of the ST\&NA and HPT\&NA materials 

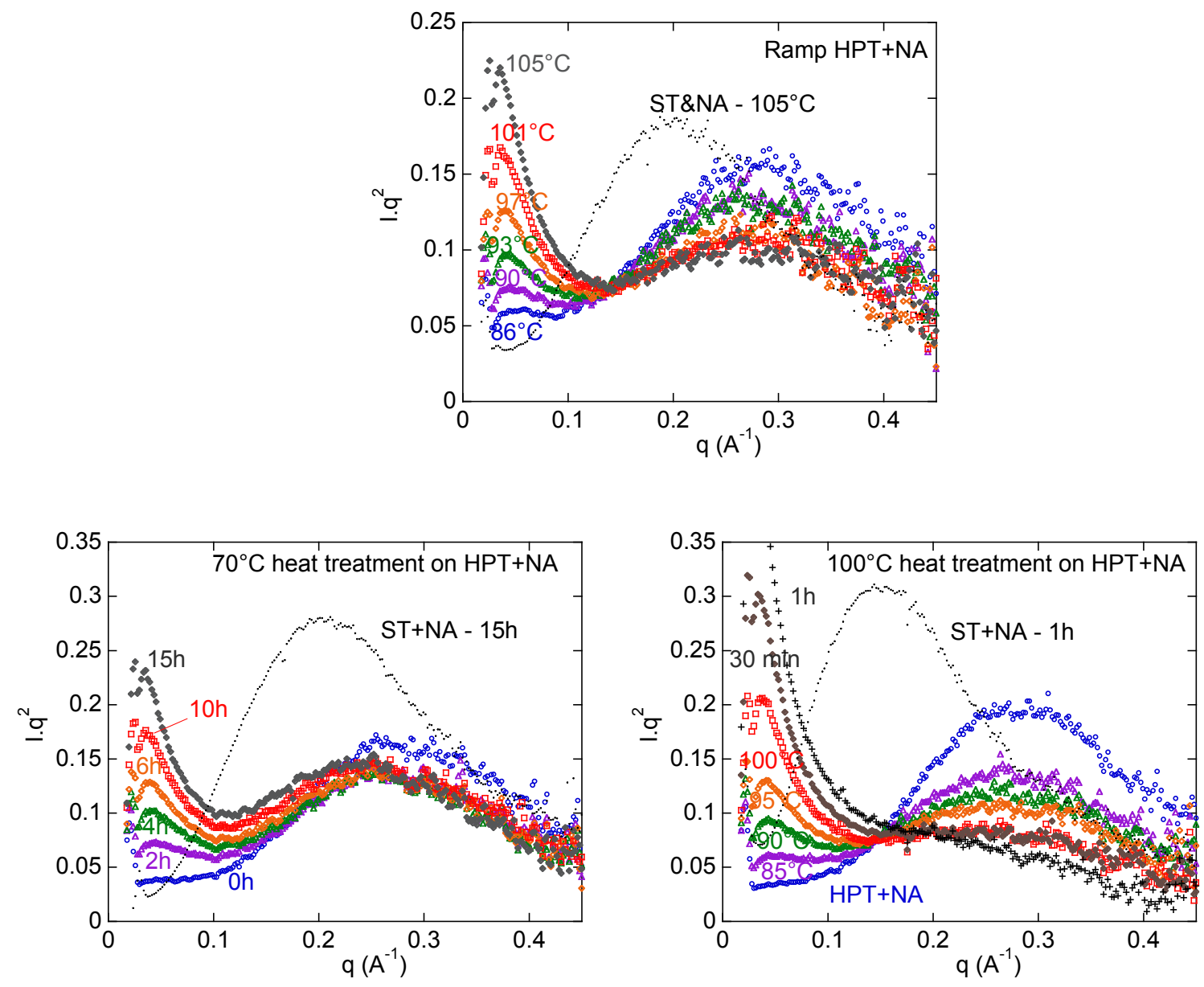

Figure 6: Kratky plots of the SAXS signal during (a) the heating ramp at $0.5 \mathrm{~K} / \mathrm{min}$ (b) isothermal ageing at $70^{\circ} \mathrm{C}$ and (c) isothermal ageing at $100^{\circ} \mathrm{C}$ for the HPT\&NA material. As a reference one SAXS curve is shown for the ST+NA material for an identical heat treatment. 


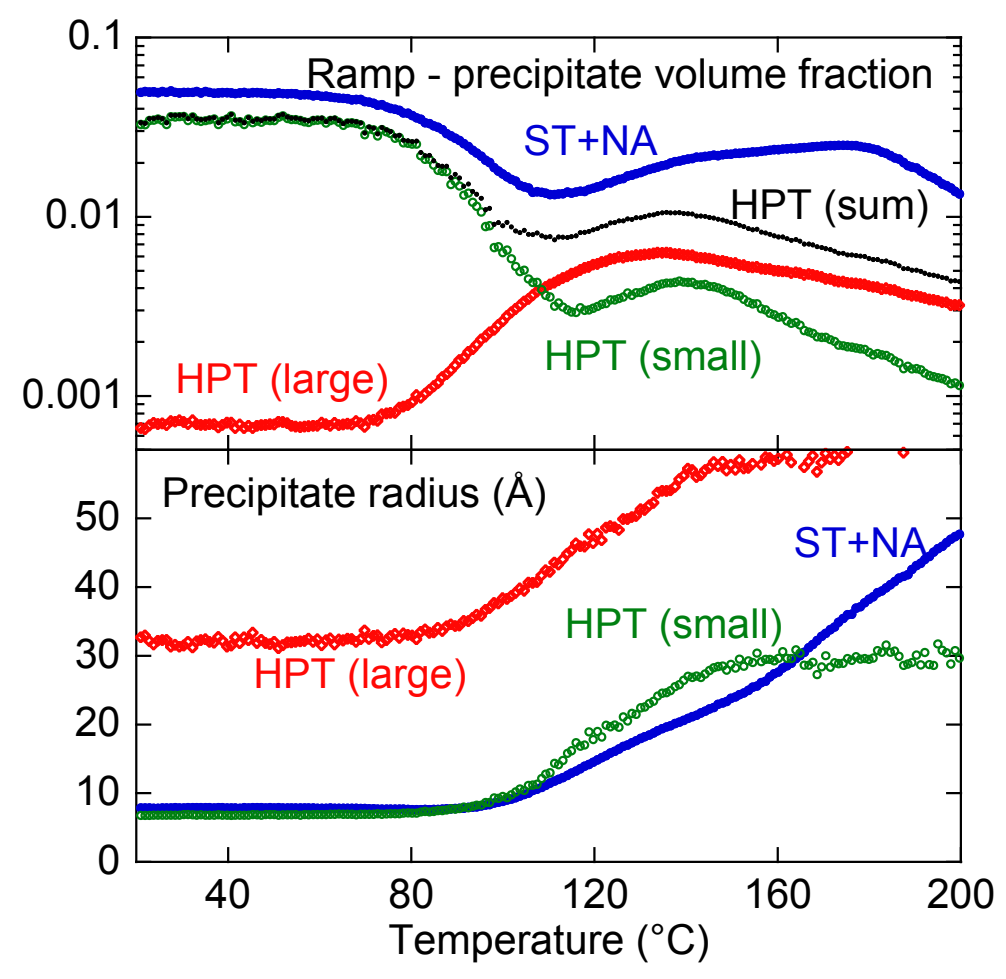

Figure 7: Evolution of precipitate volume fraction and size in the HPT+NA material subjected to ramp heating, as compared to that of the ST+NA material. For the HPT+NA material, the contributions of the small and large precipitates are separated, and the sum of the volume fraction of the two families is also represented. 


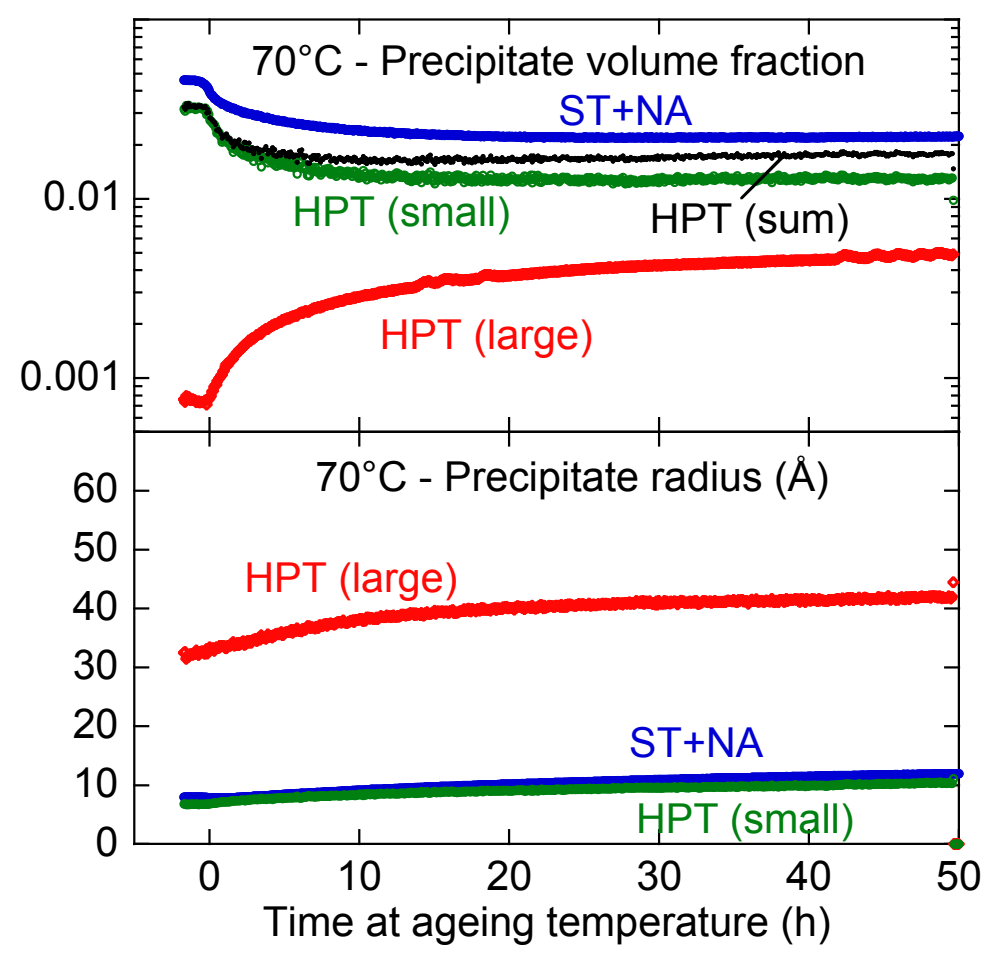

Figure 8: Evolution of precipitate volume fraction and size in the HPT $+\mathrm{NA}$ material subjected to an isothermal heat treatment at $70^{\circ} \mathrm{C}$, as compared to that of the ST+NA material. For the HPT $+\mathrm{NA}$ material, the contributions of the small and large precipitates are separated, and the sum of the volume fraction of the two families is also represented. 


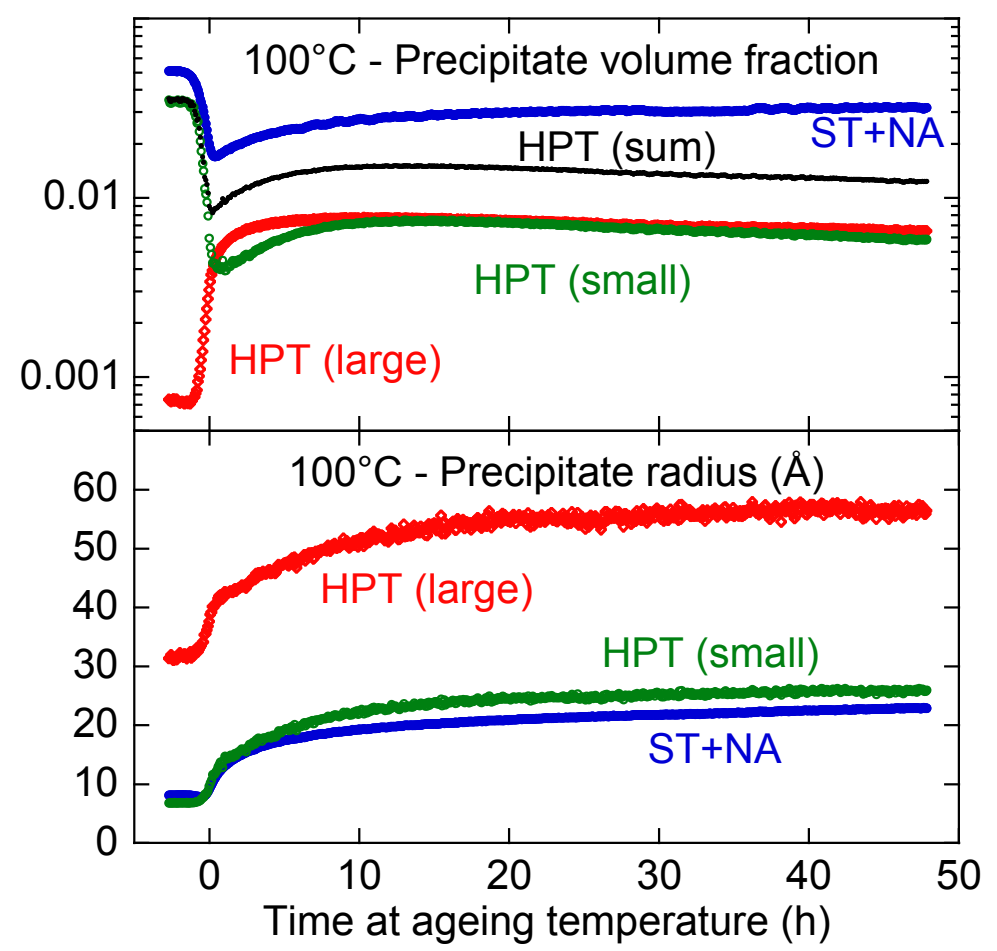

Figure 9: Evolution of precipitate volume fraction and size in the HPT $+\mathrm{NA}$ material subjected to an isothermal heat treatment at $100^{\circ} \mathrm{C}$, as compared to that of the ST+NA material. For the HPT $+\mathrm{NA}$ material, the contributions of the small and large precipitates are separated, and the sum of the volume fraction of the two families is also represented. 

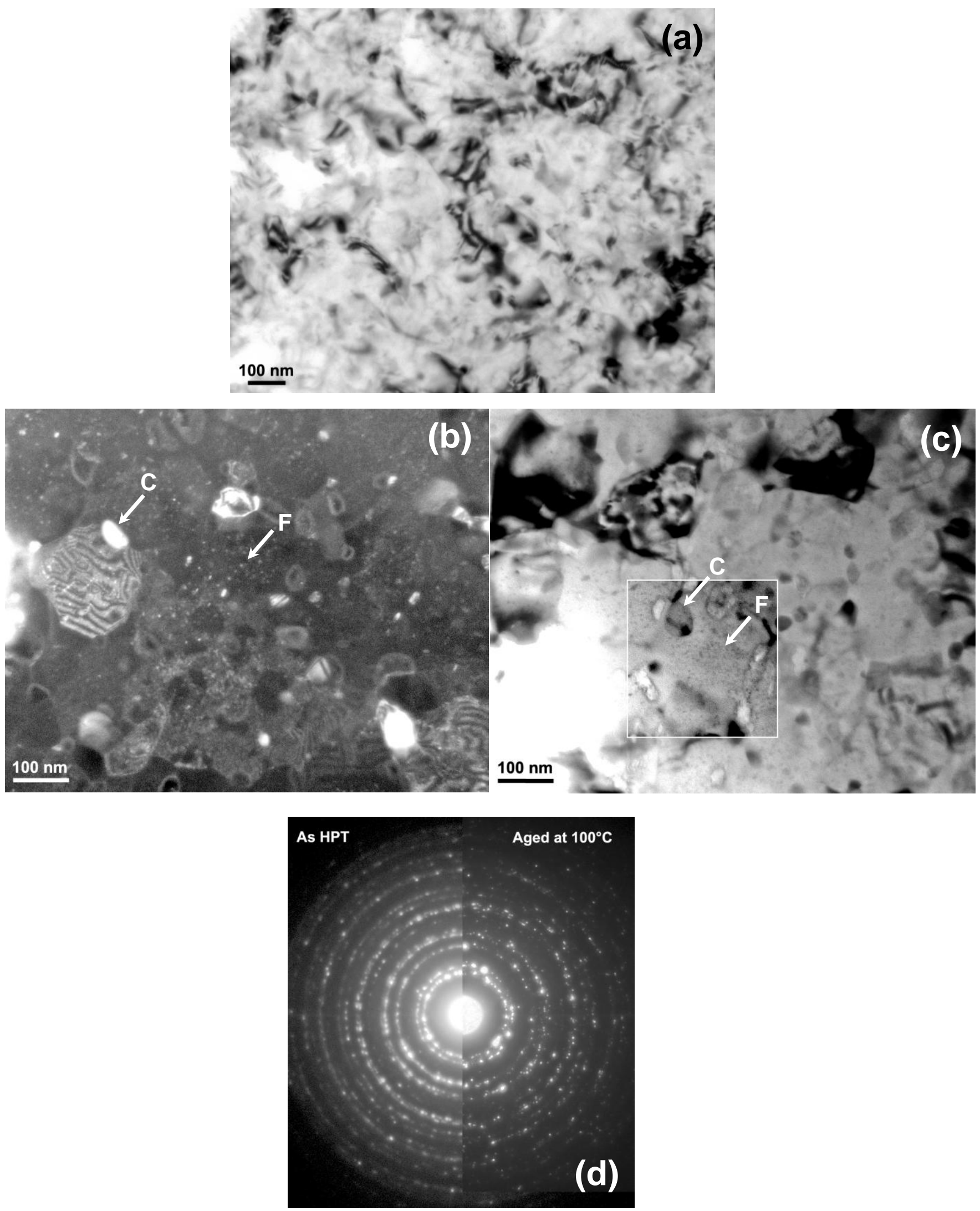

Figure 10: (a) Bright field TEM micrograph of the HPT\&NA material ; (b) Dark field and (c) Bright field TEM micrograph of the HPT material aged $48 \mathrm{~h}$ at $100^{\circ} \mathrm{C}$ showing coarse $(\mathrm{C})$ and fine (F) precipitates (note that the contrast has been enhanced for better clarity in the framed area of (c)) (d) Comparison of the electron diffraction patterns in the HPT\&NA materials and after ageing of $48 \mathrm{~h}$ at $100^{\circ} \mathrm{C}$. 


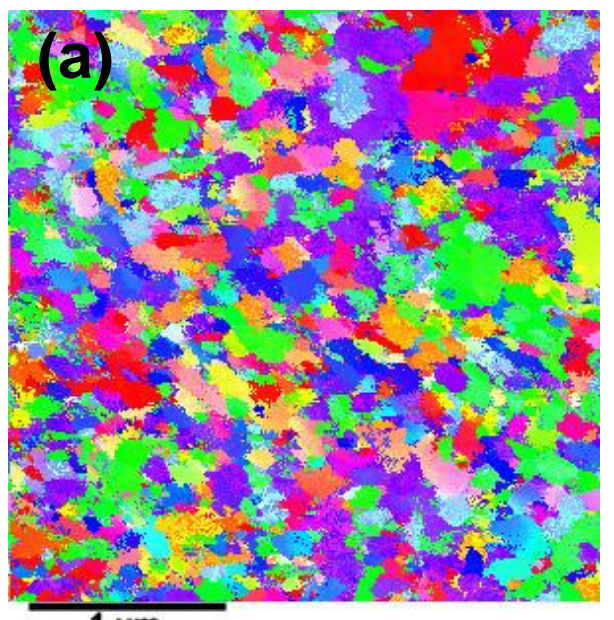

$1 \mu \mathrm{m}$
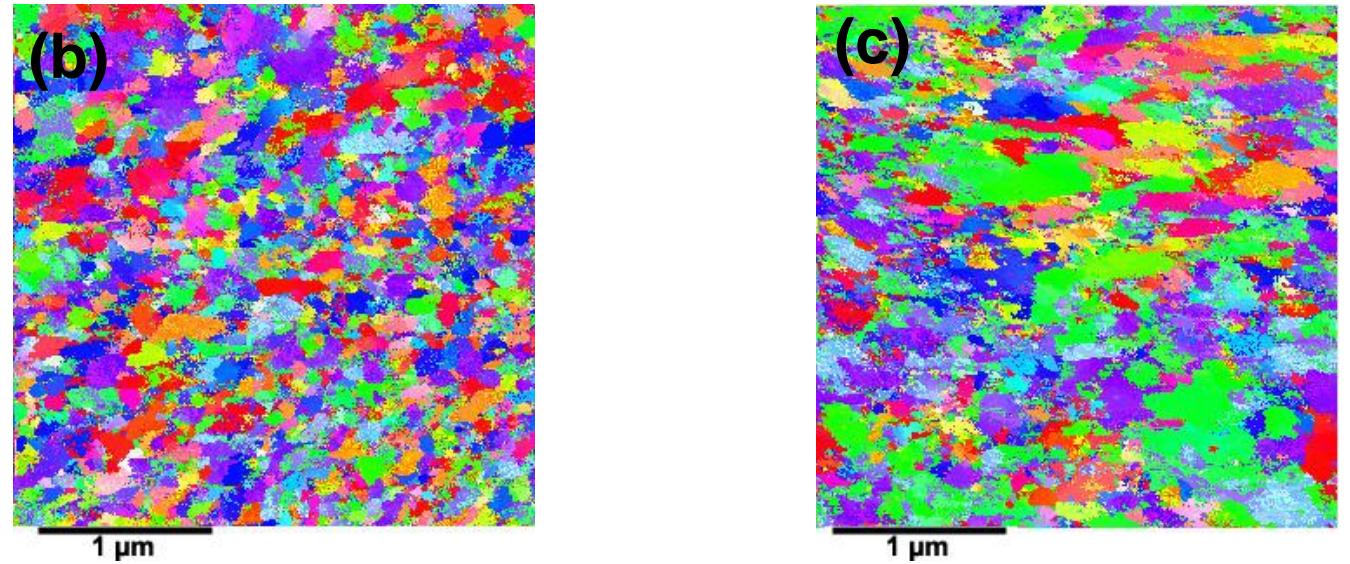

Figure 11: Orientation maps from scanning transmission electron microscopy of (a) the HPT material and after ageing at (b) $70^{\circ} \mathrm{C}$ and (c) $100^{\circ} \mathrm{C}$. 


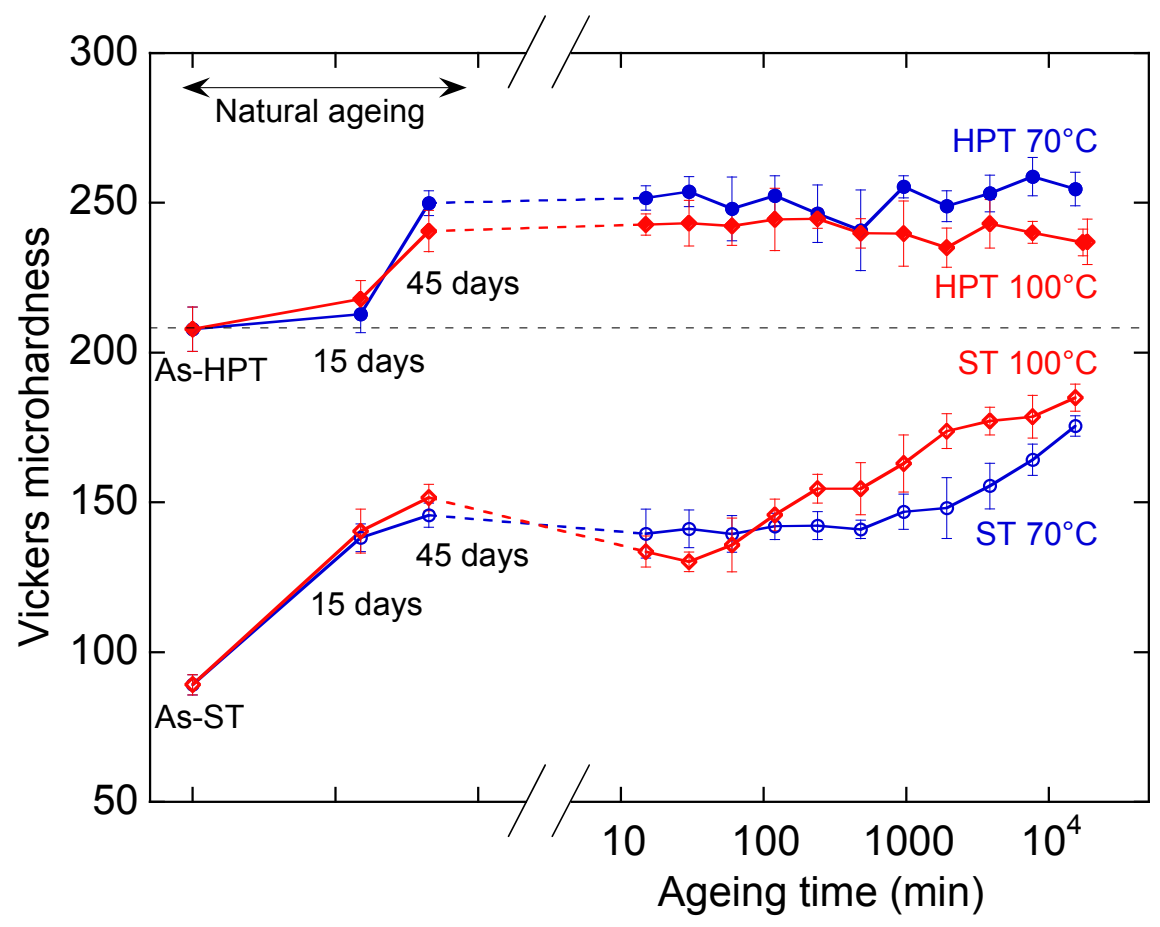

Figure 12: Evolution of microhardness during natural ageing and subsequent artificial ageing at $70^{\circ} \mathrm{C}$ and $100^{\circ} \mathrm{C}$ of the ST and HPT materials. 